\title{
Papers
}

\section{Incidence of schizophrenia in ethnic minorities in London: ecological study into interactions with environment}

\author{
J Boydell, J van Os, K McKenzie, J Allardyce, R Goel, R G McCreadie, R M Murray
}

\begin{abstract}
Objective To determine whether the incidence of schizophrenia among people from non-white ethnic minorities is greater in neighbourhoods where they constitute a smaller proportion of the total population.

Design Ecological design including retrospective study of case records to calculate the incidence of schizophrenia in the ethnic minority population across electoral wards and multi-level analysis to examine interaction between individuals and environment.

Setting 15 electoral wards in Camberwell, South London.

Participants All people aged 16 years and over who had contact with psychiatric services during 1988-97.

Main outcome measure Incidence rates of

schizophrenia according to Research Diagnostic Criteria.

Results The incidence of schizophrenia in non-white ethnic minorities increased significantly as the proportion of such minorities in the local population fell. The incidence rate ratio varied in a dose-response fashion from 2.38 (95\% confidence interval 1.49 to 3.79 ) in the third of wards where non-white ethnic minorities formed the largest proportion (28-57\%) of the local population to 4.4 (2.49 to 7.75 ) in the third of wards where they formed the smallest proportion $(8-22 \%)$.

Conclusion The incidence of schizophrenia in non-white ethnic minorities in London is greater when they comprise a smaller proportion of the local population.
\end{abstract}

\section{Introduction}

Schizophrenia is a serious illness that results in considerable burden to sufferers, carers, and society. Understanding its aetiology is extremely important. An increased incidence of schizophrenia has been consistently reported in people of African-Caribbean and African origin who are resident in the United Kingdom $^{1-3}$ and less consistently so in those of south Asian origin. ${ }^{4}$ As the excess cannot be explained by any known biological risk factor, investigation has turned to the possible role of social environment. ${ }^{6-10}$
Research in the United States has shown an association between the proportion of an ethnic minority living in a particular area and their rates of admission for mental illness, ${ }^{11}$ but a national study in the United Kingdom could not replicate these findings. ${ }^{12}$ Clarification of this issue is important not only because of what it may tell us about the aetiology of schizophrenia but also because ethnic minority groups are gradually dispersing throughout the United Kingdom.

We investigated whether the proportion of ethnic minorities in a given area was associated with their incidence rate of schizophrenia at an electoral ward level. Our hypothesis was that the incidence rate of schizophrenia in ethnic minorities would be highest in wards where they made up a smaller proportion of the population. We examined data on all new contacts with the psychiatric services over a 10 year period and used multi-level modelling techniques to examine interactions between individuals and environment.

\section{Methods}

\section{Identification of participants}

We collected clinical and demographic information on all people from a defined area of south London (previously the London Borough of Camberwell) who presented with psychosis during 1988-97. All psychiatric services for the area during this period were provided by the Bethlem Royal and Maudsley NHS Trust through hospital and community teams. We identified cases from hospital computer records by generating a list of all people admitted with any possible psychotic illness as defined by ICD-9 (international classification of diseases and related health problems, ninth revision) codes 295, 295.6, 296, 296.2, 296.4, 297, 298, and 292.1, and ICD-10 (tenth revision) codes F20, 25, 22, 30, 31.3, 31.2, 31.6, 28, 29, 12.5, 16.6, 19.5, 16.75, and 19.75. We also examined case notes of all patients from the area who had psychiatric hospital records to identify people who made contact with services but were not admitted to hospital.

We checked case records to ensure the individuals were true incident cases (that is, they had not previously had contact with psychiatric services) and rated them using the operational checklist for psychotic disorders. ${ }^{13}$ Two authors, JK and JvO, carried out the ratings, and inter-rater reliability for Research

\author{
Division of \\ Psychological \\ Medicine, Institute \\ of Psychiatry, \\ Denmark Hill, \\ London SE5 8AF \\ J Boydell \\ clinical researcher \\ K McKenzie \\ clinical researcher \\ R Goel \\ research assistant \\ R M Murray \\ professor of psychiatry \\ Department of \\ Psychiatry and \\ Neuropsychology, \\ European Graduate \\ School of \\ Neuroscience, \\ Maastricht \\ University, PO Box \\ 616, $6200 \mathrm{MD}$ \\ Maastricht, \\ Netherlands \\ $\mathrm{J}$ van Os \\ professor \\ Department of \\ Clinical Research, \\ Crichton Royal \\ Hospital, Dumfries \\ DG1 4TG \\ J Allardyce \\ lecturer \\ R G McCreadie \\ professor \\ Correspondence to: \\ J Boydell \\ j.kelly@iop.kcl.ac.uk
}

BMJ 2001;323:1-4 
Diagnostic Criteria schizophrenia ${ }^{14}$ was good $(\kappa=0.79)$. The checklist is based on phenomenological descriptions in the present state examination ${ }^{15}$ and enables a computer diagnosis of Research Diagnostic Criteria schizophrenia to be made with the associated computer program. ${ }^{16}$

\section{Ethnic and sociodemographic status}

We classified ethnicity on the basis of that recorded by the patients themselves, according to categories used by the Office of Population Censuses and Surveys. We also noted the patient's and his or her parents' place of birth, when available, and any description of colour (mental state examinations routinely comment on appearance). We used this information to determine ethnicity for those patients who did not have statements of self assigned ethnicity. A check on this method was carried out by Castle et al, who compared results with those from previous direct interviews and found no errors in 34 patients. ${ }^{17}$ Because the population projections at ward level were not accurate enough to calculate population data separately for each ethnic minority, we were able to split the population into only two groups: a white group (self assigned ethnicity white) and non-white group (all other self assigned ethnicities). The non-white population was about 40\% Caribbean, 30\% African, and 10\% other. Incident cases were assigned to either white or non-white groups. Thus the effect we measured was that of non-white ethnic minority status.

The area (about 120000 people) was divided into electoral wards of about 10000 people, which had different socioeconomic characteristics. We used the address at presentation to the services to identify wards for all incident cases. We estimated population data using the 1991 census $^{18}$ and London Research Centre projections, which include corrections for undernumeration and information about housing, mortality, and migration..$^{19}$ For the years 1992-7 our calculations were based on a linear interpolation using 1991 census data and 1997 population projection data. For the years 1988-90 we extrapolated data on the basis of the 1991-7 data. No further interpolation was attempted before 1988, so that the all analyses relate to the period

Table 1 Incidence and standardised incidence ratio of Research Diagnostic Criteria schizophrenia according to operational checklist for psychotic disorders

\begin{tabular}{lcccc} 
Ward & $\begin{array}{c}\text { No of } \\
\text { cases }\end{array}$ & $\begin{array}{c}\text { Crude } \\
\text { rate }\end{array}$ & $\begin{array}{c}\text { Adjusted rate* } \\
\mathbf{( 9 5 \%} \mathbf{~ C l})\end{array}$ & $\begin{array}{c}\text { Standardised incidence ratio† } \\
\text { (exact 95\% Cl) }\end{array}$ \\
\hline 1 & 17 & 21.7 & $21.1(12.2$ to 33.8$)$ & $0.97(0.56$ to 1.55$)$ \\
\hline 2 & 29 & 31.9 & $31(20.7$ to 44.6$)$ & $1.42(0.95$ to 2.04$)$ \\
\hline 4 & 18 & 22.5 & $14.5(8.6$ to 23$)$ & $0.67(0.39$ to 1.05$)$ \\
\hline 5 & 7 & 15.5 & $16.9(6.7$ to 35.1$)$ & $0.78(0.31$ to 1.6$)$ \\
\hline 6 & 16 & 24.6 & $21.5(12.2$ to 34.9$)$ & $0.99(0.56$ to 1.6$)$ \\
\hline 7 & 15 & 28.2 & $25.7(14.3$ to 42.5$)$ & $1.18(0.66$ to 1.95$)$ \\
\hline 8 & 19 & 38.6 & $38.4(23.1$ to 60.1$)$ & $1.76(1.06$ to 2.75$) \neq$ \\
\hline 9 & 10 & 17.1 & $18.7(8.9$ to 34.5$)$ & $0.86(0.41$ to 1.58$)$ \\
\hline 10 & 12 & 13.3 & $13.2(6.8$ to 23.1$)$ & $0.60(0.31$ to 1.06$)$ \\
\hline 11 & 15 & 17.1 & $16.9(9.4$ to 28$)$ & $0.78(0.44$ to 1.28$)$ \\
\hline 12 & 12 & 21.3 & $21.8(11.2$ to 38.1$)$ & $1.00(0.52$ to 1.75$)$ \\
\hline 13 & 19 & 28.3 & $35(21$ to 54.7$)$ & $1.61(0.97$ to 2.51$)$ \\
\hline 14 & 17 & 30 & $31.2(18.2$ to 50.1$)$ & $1.44(0.84$ to 2.3$)$ \\
\hline 15 & 7 & 8.8 & $12.4(4.9$ to 25.8$)$ & $0.57(0.23$ to 1.18$)$ \\
\hline & 9 & 14.4 & $20.1(9.1$ to 38.2$)$ & $0.92(0.42$ to 1.75$)$ \\
\hline
\end{tabular}

*Indirectly standardised to age (years), sex, and ethnic minority in total study population.

†Ratio of observed to expected cases.

‡Significant difference from standard population.
1988-97. Socioeconomic status at ward (neighbourhood) level was based on a composite deprivation score (Department of Environment index of local conditions), ${ }^{20}$ which includes unemployment, overcrowding, child poverty, lack of amenities, low earnings, no car, and low level of education (but not ethnic group).

\section{Analysis}

We carried out indirect standardisation with the Research Diagnostic Criteria rates of schizophrenia for the total 10 year population as the standard and applied them to each ward, stratifying for age, sex, and ethnic minority using the ISTDIZE procedure in the Stata statistical program (StataCorp, College Station, TX). The standardisation used the stratum specific rates of the standard population to calculate the expected number of cases for each ward and the adjusted incidence rates at ward level. We calculated the standardised incidence ratio by dividing the number of cases observed by the expected number.

By using the Stata XTPOIS multilevel Poisson regression modelling procedure, we examined two types of effects: firstly, the ward random effects-that is, are the wards different with regard to the incidence of schizophrenia; and, secondly, ward and individual fixed effects-that is, does the factor being studied make neighbourhoods different with regard to the incidence of schizophrenia. We examined the fixed effects of age, sex, and non-white ethnic minority status at the individual level and deprivation and ethnic density (proportion of ethnic minorities) in thirds of distribution (highest, middle, lowest) at ward level. We carried out multilevel Poisson regression analysis to calculate incidence rate ratios for Research Diagnostic Criteria schizophrenia for individual and ward variables and to test for interaction between non-white ethnic minority status at the individual level and proportion of non-white ethnic minority at the neighbourhood level. Interaction terms were assessed by likelihood ratio tests. We adjusted associations between schizophrenia and individual level non-white ethnic minority status and ward level proportion of non-white ethnic minority for age, sex, and ward level of deprivation.

\section{Results}

For the period 1988-97 we identified 126 (57\%) men and $96(43 \%)$ women as first onset cases, all of whom met Research Diagnostic Criteria schizophrenia. The mean age was 35.4 years (SD 18.0), and $126(57 \%)$ were non-white. Of the white patients, 10 were born in the Republic of Ireland and five were born outside the United Kingdom or Republic of Ireland.

The multi-level Poisson model of incidence of schizophrenia without covariates showed a significant random ward effect $\left(\chi^{2}=3.9, \mathrm{df}=1, \mathrm{P}<0.05\right)$, indicating that wards differed with respect to incidence of schizophrenia. The incidence, adjusted for individual level age, sex, and non-white ethnic group, varied from 12 to 38 per 100000 person years (table 1). Table 2 shows the effects of explanatory variables on incidence rate ratios at individual and neighbourhood level.

There was a significant negative interaction between individual level non-white ethnic minority status and the proportion of non-white ethnic minorities at neighbourhood level $\left(\chi^{2}=3.9, \mathrm{df}=1, \mathrm{P}<0.05\right)$. Thus 
Table 2 Influence of explanatory variables on unadjusted and adjusted incidence rate ratios

\begin{tabular}{|c|c|c|c|c|}
\hline Variable & Unadjusted ratio (95\% CI) & $P$ value & Adjusted ratio $(95 \% \mathrm{Cl})$ & $P$ value \\
\hline \multicolumn{5}{|l|}{ Individual level } \\
\hline Age (years) & 0.77 (0.71 to 0.84$)$ & $<0.001$ & $0.82(0.76$ to 0.9$)$ & 0.00 \\
\hline Sex & $0.66(0.5$ to 0.86$)$ & $<0.001$ & $0.66(0.51$ to 0.86$)$ & 0.00 \\
\hline Non-white ethnic minority & $3.75(2.87$ to 4.9$)$ & $<0.001$ & $3.28(2.49$ to 4.34$)$ & 0.00 \\
\hline \multicolumn{5}{|c|}{ Neighbourhood level equivalent of individual level } \\
\hline Proportion of non-white ethnic minorities & 1.12 (0.91 to 1.34$)$ & 0.27 & 0.83 (0.63 to 1.1$)$ & 0.2 \\
\hline \multicolumn{5}{|l|}{ Neighbourhood level } \\
\hline Deprivation & $1.06(1.01$ to 1.11$)$ & 0.01 & $1.05(0.98$ to 1.13$)$ & 0.16 \\
\hline
\end{tabular}

the analysis, stratified by thirds of proportion of non-white ethnic minorities, revealed that as the proportion in a given population decreased, the rate of schizophrenia in non-white ethnic minorities increased (table 3). Indeed, there was a "dose-response" relation with increasing incidence in non-white ethnic minorities as the proportion of such minorities in an area fell.

\section{Discussion}

Our data show an inverse dose-response relation between the proportion of people from a non-white ethnic minority group living in an area and their incidence rate for schizophrenia.

\section{Methodological issues}

The strengths of our study are that all psychiatric contacts were included (not just admissions) and that diagnostic objectivity was maximised by using computer generated diagnoses. There were, however, concurrent weaknesses. We assumed that all people with schizophrenia will come into contact with the psychiatric services. If there was differential ascertainment across wards, this could have affected the results. We took care to estimate the ward level populations as accurately as possible, but if differential underenumeration between wards had occurred during the census, this could have biased the results, although not necessarily in the direction of our findings. Our study was a retrospective case record study, but clinical staff rotated through jobs that covered the different electoral wards. Our results would have been biased only if case notes were recorded differently for different electoral wards, and this is unlikely. Finally, our methods could be criticised because the white group contained individuals from white ethnic minority groups, most of whom were born in the Republic of Ireland.

\section{Previous findings}

Our results are consistent with those from studies in the United States that have found an inverse correlation between an individual's risk of mental illness and the relative proportion of their ethnic group living in an area. ${ }^{11} 22$ Cochrane and Bal calculated first and total admission rates for schizophrenia for the whole of England in 1981 for 15 different ethnic groups on the basis of place of birth. ${ }^{12}$ Their analysis between and within groups did not find that rates increased as the relative size of the ethnic group decreased, with the exception that there was a strong significant negative correlation $(-0.86, \quad \mathrm{P}<0.01)$ between admission rates for schizophrenia and relative size of the population born in the Republic of Ireland.
Unlike other studies, we used incidence data rather than data on hospital admission. Moreover, we were able to look at smaller areas that have less variance in coverage and access to services and used appropriate multilevel statistical techniques.

\section{Interpretation}

Our results could be due to selection bias in that people who choose to live in areas where they are more isolated from their own ethnic community, perhaps during a prodromal period, could be more at risk of developing schizophrenia. This seems unlikely as only limited choice is possible because most housing in Camberwell is local authority (public) housing.

Our results could be confounded by economic deprivation. We have tried to control for this, but there still could have been an uncontrolled effect if the nonwhite people living in predominantly white areas were more deprived than those in areas with a higher proportion of non-white people. We believe that this is unlikely because the wards with the highest proportion of non-white people are extremely and uniformly deprived to a level not reached anywhere in the mainly white neighbourhoods.

To invalidate our results any confounder, such as drug misuse or presence of a particularly high risk group, would have to act differentially across neighbourhoods, exerting maximum effect in neighbourhoods with a low proportion of non-white ethnic minorities, less effect on those with medium proportion, and least effect on those with a high proportion.

\section{Mechanism}

Our findings point towards there being a social risk factor for the increased rate of schizophrenia reported in non-white ethnic minorities in the United Kingdom. What seems to be important is the absolute number or concentration of people from non-white ethnic groups in the immediate vicinity. Thus, a possible mechanism is increased exposure to, and/or reduced protection against, stress and life events. Specific stresses for people in ethnic minority groups could be overt discrimination, institutionalised racism, and perceived alienation, isolation, and anomie. ${ }^{23}$ The more isolated a member of an

Table 3 Change in incidence and incidence rate ratios for research diagnostic criteria for schizophrenia according to operational checklist for psychotic disorders with proportion of ethnic minority

\begin{tabular}{|c|c|c|c|}
\hline $\begin{array}{l}\text { Proportion of non-white ethnic } \\
\text { minorities }\end{array}$ & $\begin{array}{l}\text { Incidence per } \\
100000\end{array}$ & Unadjusted ratio (95\% Cl) & Adjusted ratio* $(95 \% \mathrm{CI})$ \\
\hline Lowest third (8-22.8\%) & 52.6 & $5.15(2.96 \text { to } 8.96)^{*}$ & $4.4(2.49$ to 7.75$) \dagger$ \\
\hline Middle third (23-28.1\%) & 59.0 & $3.89(2.58 \text { to } 5.89)^{*}$ & $3.63(2.38$ to 5.54$) \dagger$ \\
\hline Highest third (28.2-57\%) & 36.9 & $2.32(1.48 \text { to } 3.63)^{*}$ & 2.38 (1.49 to 3.79$) \dagger$ \\
\hline
\end{tabular}

${ }^{*}$ Adjusted for age (years), sex, and ward deprivation z score. $\dagger P<0.001$. 


\section{What is already known on this topic}

An increased incidence of schizophrenia has been reported in several ethnic minorities in the United Kingdom

Biological risk factors do not seem to explain this

Reports from the United States have shown an association between the proportion of an ethnic minority living in an area and their admission rates for mental illness in general

\section{What this study adds}

The lower the proportion of non-white ethnic minorities in a local area the higher the incidence of schizophrenia in those minorities

ethnic minority, the more likely he or she may be to encounter such stresses. ${ }^{24}$ People from ethnic minorities may be more likely to be singled out or be more vulnerable when they are in a small minority. Reduced protection from the effects of such stresses could be due to decreased social networks or social buffers in small or dispersed ethnic minority populations.

Contributors: RMM, RGM, JB, and JA designed the study. JB, $\mathrm{RG}$, and $\mathrm{JvO}$ collected the data. $\mathrm{KM}, \mathrm{JB}$, and $\mathrm{JvO}$ discussed the analysis, which was carried out by JvO. JB, JvO, KM, RG, and RGM discussed and interpreted the results. The paper was written by JB, $\mathrm{KM}, \mathrm{JvO}$, and RMM. JB is the guarantor for the paper. Funding: JB was supported by the Stanley Foundation and the Gordon Small Trust.

Competing interests: None declared.

1 Harrison G, Owens D, Holton A, Neilson D, Boot D. A prospective study of severe mental disorder in Afro-Caribbean patients. Psychol Med $1988 ; 18: 643-57$

2 Wessely S, Castle D, Der G, Murray R. Schizophrenia and AfroCaribbeans. A case-control study. Br J Psychiatry 1991;159:795-801.

3 Van Os J, Castle DJ, Takei N, Der G, Murray RM. Psychotic illness in ethnic minorities: clarification from the 1991 census. Psychol Med 1996;26:203-8
4 King M, Coker E, Leavey G, Hoare A, Johnson-Sabine E. Incidence of psychotic illness in London: comparison of ethnic groups. BMJ 1994;309:1115-9.

5 Bhugra D, Leff J, Mallett R, Der G, Corridan B, Rudge S. Incidence and outcome of schizophrenia in whites, African-Caribbeans and Asians in London. Psychol Med 1997:27:791-8.

6 McKenzie K, Van Os J, Fahy T, Jones P, Harvey I, Toone B, et al. Psychosis with good prognosis in Afro-Caribbean people now living in the United Kingdom. BMJ 1995;311:1325-8

7 Hutchinson G, Takei N, Fahy TA, Bhugra D, Gilvarry C, Moran P, et al. Morbid risk of schizophrenia in first-degree relatives of white and African-Caribbean patients with psychosis. Br J Psychiatry 1996;169:77680.

8 Hutchinson G, Takei N, Bhugra D, Fahy TA, Gilvarry C, Mallett R, et al. Increased rate of psychosis among African-Caribbeans in Britain is not due to an excess of pregnancy and birth complications. Br J Psychiatry 1997;171:145-7.

9 Hutchinson G, Mallett R, Fletcher H. Are the increased rates of psychosis reported for the population of Caribbean origin in Britain an urban effect? Int Rev Psychiatry 1999;11:122-8.

10 Sharpley MS, Hutchinson G, Murray RM, McKenzie K. Understanding the excess of psychosis among the African-Caribbean population in England: review of current hypotheses. Br J Psychiatry 2001;178(suppl 40):60-8.

11 Halpern D. Minorities and mental health. Soc Sci Med 1993;36:597-607.

12 Cochrane R, Bal SS. Ethnic density is unrelated to incidence of schizophrenia. Br J Psychiatry 1988;153:363-6.

13 McGuffin P, Farmer A, Harvey I. A polydiagnostic application of operational criteria in studies of psychotic illness. Development and reliability of the OPCRIT system. Arch Gen Psychiatry 1991;48:764-70.

14 Spitzer RL, Endicott J, Robins E. Research diagnostic criteria: rationale and reliability. Arch Gen Psychiatry 1978;35:773-82.

15 Wing JK, Cooper JE, Sartorius N. The measurement and classification of psychiatric symptoms. London: Cambridge University Press, 1974.

16 Williams J, Farmer AE, Arkenheil M, Kaufmann CA, McGuffin P. A multicentre inter-rater reliability study using the OPCRIT computerized diagnostic system. Psychol Med 1996;26:775-83.

17 Castle D, Wessely S, Der G, Murray RM. The incidence of operationally defined schizophrenia in Camberwell, 1965-84. Br J Psychiatry 1991;159:790-4.

18 Office of Population Census and Surveys Population Estimates Unit. 1991 census, Local base statistics. London: Office for National Statistics, 1991.

19 London Research Centre. Round projections and methodology. London: London Research Centre, 1997.

20 Department of the Environment. Index of local conditions. London: Office for National Statistics, 1991

21 Rabkin J. Ethnic density and psychiatric hospitalization: hazards of minority status Am J Psychiatry 1979;136:1562-6.

22 Murphy HBM. Migration and the major mental disorders: a reappraisal. In: Kantor M, ed. Proceedings of the fifth annual conference on community mental health research. Springfield, IL: Charles C Thomas, 1965:5-28.

23 Williams D. Racism and health: a research agenda. Ethn Dis 1996;6:1-6.

24 King G, Williams DR. Race and health a multi-dimensional approach to African-American health. In: Amik BC III, Levins S, Tarlov AR, Chapman Walsh D, eds. Society and health. New York: Oxford University Press, 1995:93-130.

(Accepted 29 August 2001) 